Article

\title{
Improved Forecasting of Extreme Monthly Reservoir Inflow Using an Analogue-Based Forecasting Method: A Case Study of the Sirikit Dam in Thailand
}

\author{
Somchit Amnatsan ${ }^{1,2, *}$, Sayaka Yoshikawa ${ }^{2}$ and Shinjiro Kanae ${ }^{2}$ \\ 1 Water Management and Maintenance Division, Regional Irrigation Office 2, Lampang 52100, Thailand \\ 2 Department of Civil and Environmental Engineering, School of Environment and Society, \\ Tokyo Institute of Technology, 2-12-1-M1-6 Ookayama, Meguro-ku, Tokyo 152-8552, Japan; \\ yoshikawa.s.ad@m.titech.ac.jp (S.Y.); kanae@cv.titech.ac.jp (S.K.) \\ * Correspondence: somnatsan@yahoo.com; Tel.: +66-86-859-6488
}

Received: 24 September 2018; Accepted: 5 November 2018; Published: 9 November 2018

check for updates

\begin{abstract}
Reservoir inflow forecasting is crucial for appropriate reservoir management, especially in the flood season. Forecasting for this season must be sufficiently accurate and timely to allow dam managers to release water gradually for flood control in downstream areas. Recently, several models and methodologies have been developed and applied for inflow forecasting, with good results. Nevertheless, most were reported to have weaknesses in capturing the peak flow, especially rare extreme flows. In this study, an analogue-based forecasting method, designated the variation analogue method (VAM), was developed to overcome this weakness. This method, the wavelet artificial neural network (WANN) model, and the weighted mean analogue method (WMAM) were used to forecast the monthly reservoir inflow of the Sirikit Dam, located in the Nan River Basin, one of the eight sub-basins of the Chao Phraya River Basin in Thailand. It is one of four major dams in the Chao Phraya Basin, with a maximum storage of $10.64 \mathrm{~km}^{3}$, which supplies water to 22 provinces in this basin, covering an irrigation area of 1,513,465 hectares. Due to the huge extreme monthly inflow in August, with inflow of more than $3 \mathrm{~km}^{3}$ in 1985 and 2011, monthly or longer lead time inflow forecasting is needed for proper water and flood control management of this dam. The results of forecasting indicate that the WANN model provided good forecasting for whole-year forecasting including both low-flow and high-flow patterns, while the WMAM model provided only satisfactory results. The VAM showed the best forecasting performance and captured the extreme inflow of the Sirikit Dam well. For the high-flow period (July-September), the WANN model provided only satisfactory results, while those of the WMAM were markedly poorer than for the whole year. The VAM showed the best capture of flow in this period, especially for extreme flow conditions that the WANN and WMAM models could not capture.
\end{abstract}

Keywords: reservoir inflow forecasting; artificial neural network; wavelet artificial neural network; weighted mean analogue; variation analogue

\section{Introduction}

Reservoirs are manmade structures that are widely used in water resource management, and are recognized as some of the most efficient infrastructure components in integrated water resource management and development [1]. Reservoirs are among the major solutions to water demand and water-related problems, including irrigation, hydropower, urban and industrial water supply, conservation of ecology, and flood control. Nevertheless, there are several factors that affect the performance of the reservoir system, for example, the reservoir sedimentation [2] and the reservoir 
operation. In reservoir operation, care is required, especially for multipurpose reservoirs where there may be a number of potentially conflicting objectives. For water supply, operations should keep reservoirs as full as possible, whereas flood control requires reservoirs to be kept as empty as possible to allow the capture of flood water [3]. Reservoirs should be neither partially empty at the end of the rainy season nor full at the time of a series of peak floods that lead to heavy releases, causing floods in downstream areas [4]. Due to its complexity, reservoir operation is a challenging problem for water resource planners and managers. To optimize operating rules, many optimization and simulation models have been developed and applied over the past several decades [5-9]. However, these operating rules are not easy to implement, as appropriate reservoir operations depend on the accuracy of inflow forecasting and the operating time horizon [10]. Accurate inflow prediction is not only an important non-engineering measure to ensure flood-control safety and increase water resource use efficiency, but also can provide guidance for reservoir planning and management, because streamflow is the major input into reservoirs [11,12].

Due to its importance, several models and methodologies for reservoir inflow forecasting have been developed and applied in real-world situations [13]. One method that is widely used to forecast reservoir inflow is the artificial neural network (ANN) model. Although this is a black-box model in which the internal structure of the process involved cannot be understood, it has many advantages from the viewpoint of practical application. First, it is able to recognize the relation between the input and output variables without explicit physical consideration [14]. Second, it is very convenient to review the model when the data of interest are suspected as having changed. It can be recalculated as soon as new data are available with low cost and time requirements. Third, once the model is developed, it can be adapted very flexibly to other areas or for other purposes. In addition to these advantages, ANN models have been shown to be applicable to hydrology, including reservoir inflow prediction $[14,15]$. There have been several reports of the application of the ANN model for predicting short-term reservoir inflow at hourly and daily time scales $[16,17]$. Most studies have concluded that the ANN model provides satisfactory forecasting results. The ANN model can also be applied to forecast long-term and seasonal reservoir inflow as reported in several studies [18-20]. Some studies attempted to improve forecasting results by incorporating sea-surface temperature (SST) and climatic indices as inputs of the ANN model [21]. Most studies reported the good prediction results and the incorporation of SST provide improved predictions relative to the same model using only reservoir inflows.

Although ANNs have been used successfully in various fields, the precision of the results has still required improvement in many cases. Several hybrid ANN models have been proposed to fulfill this requirement. Kim and Valdés [22] developed a model for drought forecasting in the Conchos River Basin in Mexico, making use of the ability of neural networks to model and forecast nonlinear and non-stationary time series and the ability of wavelet transforms to provide useful decompositions of an original time series. The results indicated that the conjunction model significantly improved the ability of neural networks to forecast the index regional drought. A similar study which indicated the successful integration of the ANN and wavelet analysis to predict water levels in the Nan River, Thailand, can be found in the work of Amnatsan et al. [23].

Another technique that has been widely used in forecasting is the analogue method (AM), which was first introduced by Lorenz in 1969 to predict the evolution of the states of a dynamic system [24]. This is the simplest statistical technique that can establish nonlinear relationships between variables in a straightforward manner [25]. The analogue forecasting approach is based on the hypothesis that two relatively similar synoptic situations may produce similar local effects [26]. This approach has two main advantages and has been commonly used in weather prediction. First, the use of observed weather patterns helps to maintain the local-scale weather in the simulated field. Second, it is easy to construct scenarios for non-normally distributed variables, such as daily precipitation, because the AM does not assume the form of probability distribution of downscaled variables [27]. There have been many reports of successful implementation of the AM in weather 
prediction $[25,26,28,29]$. However, there have been few reports regarding its application to streamflow forecasting. Bellier et al. [30] evaluated probabilistic flood forecasting on the Rhone River using ensemble- and analogue-based precipitation forecasts. They reported that forecasting performance of the two methods for the peak amplitude and peak timing of floods was very similar. Svensson [31] performed flow forecasting based on flow persistence and historical flow analogues. The river flows at one and three months in the future at 93 individual river flow stations across the United Kingdom were forecast using two historical AMs, i.e., the weighted mean method and the shifted weighted mean method. The results indicated that forecasts based on persistence of the previous month's flow generally outperformed the analogue approach, particularly for slowly responding catchments with large underground water storage in aquifers. For the weighted-mean AM, the forecasting performance was increased with the length of historical flow records. The considerable success used of the weighted-mean in an interlayer forward validated scheme was reported in Panagoulia [32].

In this study, the wavelet artificial neural network (WANN) and the weighted mean AM (WMAM) were used to forecast the monthly reservoir inflows of the Sirikit Dam in Thailand. Monthly and seasonal inflow forecasting are very important for proper management of this multipurpose dam, which has a large catchment area of $13,130 \mathrm{~km}^{2}$ and maximum storage of $10.64 \mathrm{~km}^{3}$. This is one of four major dams that supply water to 22 provinces in the Chao Phraya Basin, covering an irrigation area of 1,513,465 hectares. Difficulty in the operation of this dam occurs mainly in the monsoon season, especially in July to September, the months which account for about $50 \%$ of the annual inflow. During this period, the dam managers have to decide whether to keep or release water. They have to retain sufficient water to supply demand in the next dry season, but for downstream flood control they must not keep too much water. As the capacity of the downstream river is limited, large amounts of water cannot be released in too short a time. An incorrect decision due to lack of an accurate and timely inflow forecast will lead to excessive release in a short time, resulting in flooding in downstream areas. On the other hand, a long forecast lead time will allow dam managers to release water gradually. Therefore, monthly or seasonal weather and reservoir inflow forecasting are crucial for proper management of this dam [33].

In addition to the WANN and WMAM methods, a forecasting method designated as the variation analogue method (VAM) was developed and employed to forecast the reservoir inflow of this dam. This study was performed to evaluate the performance of different forecasting methods in predicting the reservoir inflow, especially with regard to predicting extreme flow. Many researchers have reported that ANN-based models cannot predict extreme values in river flow $[34,35]$. The WMAM, which was found to show good predictive performance for a low-response watershed [31], may not be able to forecast the peak flow for the high-response catchment of the Sirikit Dam.

Several previous studies have indicated that SSTs and ocean indices are associated with the seasonal and interannual climate of Thailand [36-39], and therefore the variability of rainfall and reservoir inflows may be associated with SST anomalies. Manusthiparom [40] reported that adding SSTs as ANN inputs significantly improved the results of monthly rainfall and runoff forecasting for the Chao Phraya River Basin. In this study, we incorporated SSTs and ocean indices into the WANN and the VAM to improve the performance of inflow forecasting. Their forecasting performance was compared using four indicators: the root mean square error (RMSE), the correlation (R), the Nash-Sutcliffe efficiency index (EI), and the coefficient of determination (CD).

\section{Study Area and Methods}

\subsection{Study Area and Data}

The Sirikit Dam is located in the Nan River Basin, one of the eight sub-basins of the Chao Phraya River Basin in Thailand, as shown in Figure 1. It is the largest earth-filled dam in Thailand, with a catchment area of $13,130 \mathrm{~km}^{2}$ and a maximum storage of $10.64 \mathrm{~km}^{3}$. The main functions of 
this dam are flood prevention, water supply for domestic use, ecological conservation, agriculture, industry, fishing, and as an important tourist attraction.

The sources of data used in this study are listed in Table 1. The monthly reservoir inflow data of Sirikit Dam used in this study were obtained from the Electricity Generating Authority of Thailand (EGAT). The data were for the period from January 1974 to December 2014.

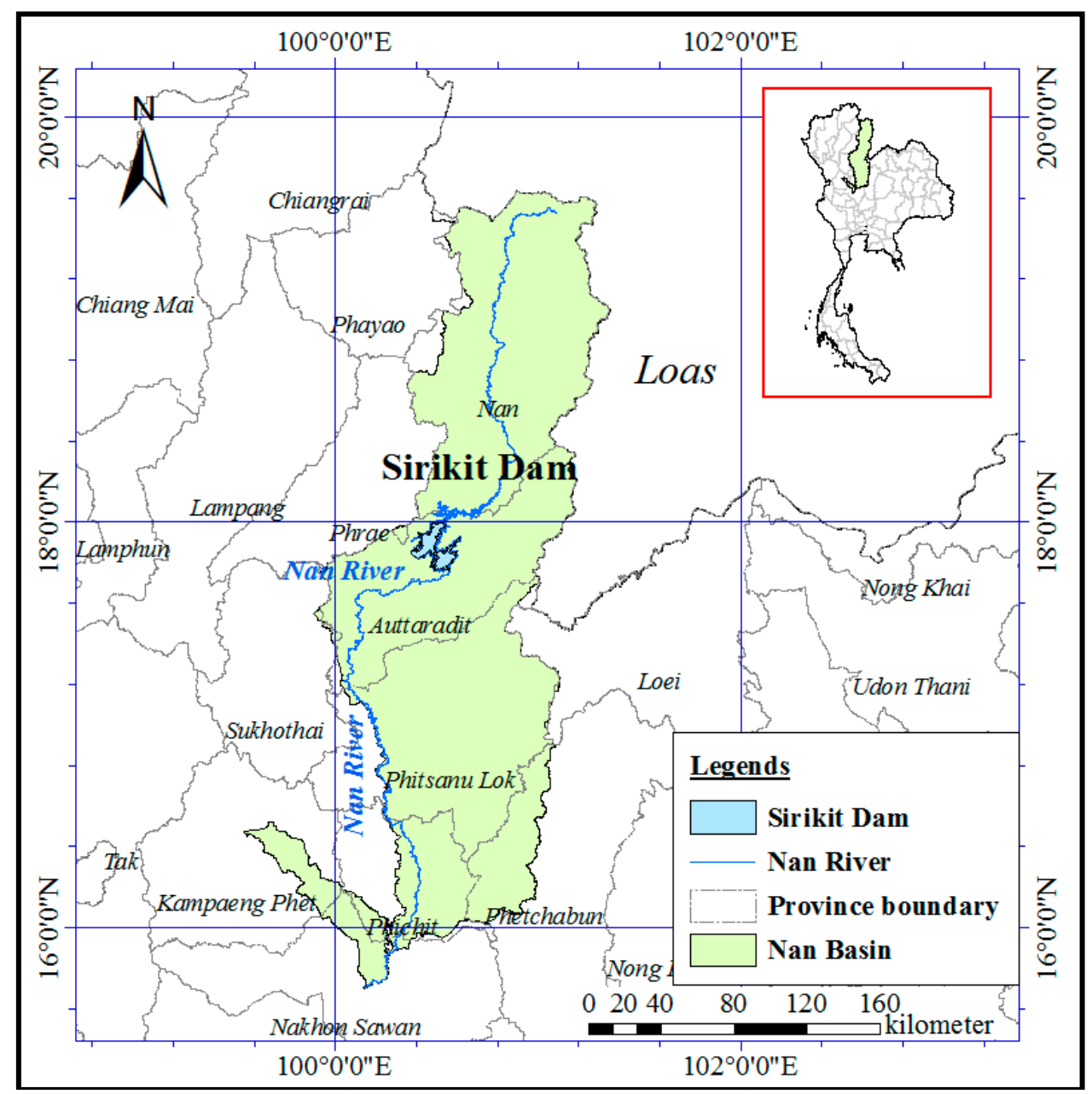

Figure 1. Location of the Sirikit Dam.

Table 1. Sources of data used in this study.

\begin{tabular}{|c|c|c|}
\hline Data Used & SST Regions/Ocean Index Name & Source \\
\hline Sea-surface temperature (SST) & $\begin{array}{c}\text { Niño } 1+2 \\
\text { Niño } 3 \\
\text { Niño } 3.4 \\
\text { Niño } 4 \\
\text { Pacific Ocean } \\
\text { South China Sea } \\
\text { Andaman Sea }\end{array}$ & $\begin{array}{c}\text { The U.S. National Oceanic and } \\
\text { Atmospheric Administration } \\
\text { (NOAA) }\end{array}$ \\
\hline \multirow{2}{*}{ Ocean index } & Southern Oscillation Index (SOI) & \\
\hline & Dipole Mode Index (DMI) & $\begin{array}{l}\text { Japan Agency for Marine-Earth } \\
\text { Science and Technology } \\
\text { (JAMSTEC) }\end{array}$ \\
\hline Monthly reservoir inflow & & $\begin{array}{c}\text { Electricity Generating Authority } \\
\text { of Thailand (EGAT) }\end{array}$ \\
\hline
\end{tabular}


The SSTs and the El Niño/La Niña Southern Oscillation (ENSO) indices in Niño 3, Niño 4, Niño $1+2$, and Niño 3.4 regions, including the Southern Oscillation Index (SOI), were used in this study. The data were taken from the U.S. National Oceanic and Atmospheric Administration (NOAA), available at http://www.cpc.ncep.noaa.gov/. These are monthly data from January 1950 to December 2014.

In addition, the Dipole Mode Index (DMI) was also used as another ocean index. The DMI, which represents the intensity of the Indian Ocean Dipole (IOD), shows the anomalous SSTs between the western Indian Ocean and the southeastern Indian Ocean. The DMI data were obtained from the Japan Agency for Marine-Earth Science and Technology (JAMSTEC) website (http:/ / www.jamstec.go. jp).

Additional SST data for the Pacific Ocean, the South China Sea, and the Andaman Sea were also used in this study to improve the accuracy of reservoir-inflow forecasting. The Extended Reconstructed Sea Surface Temperature (ERSST) version 3b dataset, a global monthly SST analysis derived from the International Comprehensive Ocean-Atmosphere Dataset with missing data filled in by statistical methods, was taken from the U.S. National Oceanic and Atmospheric Administration (NOAA), available at http:/ / www.ncdc.noaa.gov.

For the WANN forecasts, data from January 1974 to December 2004 were used for training, from January 2005 to December 2010 for validation, and from January 2011 to December 2014 for testing of the models. For the WMAM and VAM forecasts, the inflow data from January 1974 to December 2004 were used as historical analogues for forecasting inflow from January 2005 to December 2014. This forecasting period corresponded to the validation and testing periods in the WANN models.

\subsection{Wavelet Artificial Neural Network}

The WANN is a hybrid version of the ANN model in which wavelet analysis is used as a data pre-processing technique to improve accuracy. According to the investigation of the American Society of Civil Engineers (ASCE) Task Committee on Application of Artificial Neural Networks in Hydrology [14] that a feed-forward network with a single hidden with an arbitrary number of sigmoidal hidden nodes can approximate any continuous function, a multilayer perceptron (MLP) feedforward network with one hidden layer was adopted in this study. The network was trained in a supervised manner with an error back-propagation algorithm. As suggested in Panagoulia et al. [41], input variables should be "first stage" selected, depending on their robustness, from an inclusive set which influences the physical model underlying the ANN structure with the constraint of minimizing redundancy and noise. In the second stage of selection, an association via statistics must be established to determine those first stage input variables that are maximally and distinctly connected to the major internal model variables. In this study, the reservoir inflow was selected and the autocorrelation analysis between different lag versions of those inflows was performed in an initial experiment. After that, other inputs were selected and cross-correlation analyses between the different lag versions of those inputs and the inflows were performed. Trials with changes in activation function, learning rate, number of hidden neurons, and momentum of the ANN network were also performed to obtain the best forecasting results. After obtaining the best forecasting results for each input dataset, the original input data were then decomposed into their detailed (high frequency) and approximated (low frequency) components by a discrete wavelet transform. Based on the study of Wang et al. [42], using different mother wavelets in the wavelet neural network affected the accuracy of prediction results. In this study, the Haar wavelet, the simplest and oldest of all wavelet functions [43], was used. This wavelet function provided a good prediction result in the study of Wang et al. [42]. The simplicity of this wavelet function facilitated the decomposition process and consequently supported practical implementation. Only one level of decomposition was used in this study. After decomposition, the decomposed data were used as the input for the ANN model. The architecture of the WANN model used in this study is shown in Figure 2. 


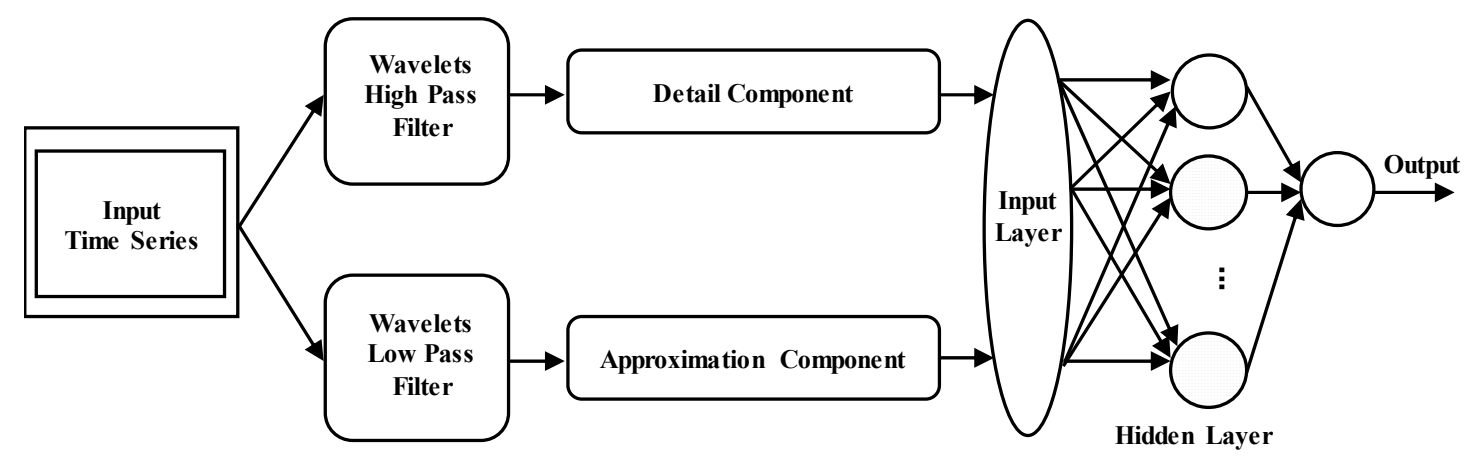

Figure 2. Architecture of the wavelet artificial neural network (WANN) model.

\subsection{Weighted Mean Analogue Method}

The full details of the WMAM were presented by Svensson [31]. In the present study, the forecast was obtained by first calculating the reservoir inflow anomalies. In the calculation, monthly reservoir inflows were transformed to the log form to ensure that the distribution was similar to a normal distribution, and when assessing the similarity of the analogues to the recent past, the highest inflows became less extreme. After log transformation, standardized reservoir inflow anomalies were calculated for use in the analysis as follows. For each of the 12 calendar months (mon), the mean reservoir inflow $\left(m_{m o n}\right)$, and standard deviation $\left(s_{m o n}\right)$ were calculated from the log-transformed monthly reservoir inflow $\left(q_{t}\right)$. A series of standardized monthly anomalies $\left(a_{t}\right)$ was then calculated as:

$$
a_{t}=\frac{q_{t}-m_{m o n}}{s_{m o n}}
$$

where $t$ denotes the serial number of the month, starting from January 1974, and mon refers to the calendar month corresponding to $t$. Forecasts could be made once the observed data for the latest month were received by comparing the monthly anomalies of the most recent past months with all possible historical sequences of anomalies covering the same months of the year. From this annual series of potential analogues based on the RMSE, the $N_{\text {ana }}$ historical analogues most similar to those of the recent past were selected. Then, we used the inverse of these RMSEs to weight the inflow anomalies in the months following the analogues to obtain the WMAM forecast. The RMSE was calculated for each potential analogue in the observed record as follows:

$$
\mathrm{RMSE}=\sqrt{\frac{1}{D_{\text {ana }}} \sum_{k=1}^{D_{\text {ana }}}\left(a_{p}(k)-a_{r}(k)\right)^{2}}
$$

where $a_{p}(k)$ is the inflow anomaly for each month $k$ in the potential analogue of duration $D_{a n a}$, and $a_{r}(k)$ is the corresponding inflow anomaly in the recent past. The RMSEs for the selected $N_{a n a}$ analogues were used to calculate the weight, $w$, for each analogue as follows:

$$
w(n)=\frac{1}{\operatorname{RMSE}(n)} / \sum_{n=1}^{N_{\text {ana }}} \frac{1}{\operatorname{RMSE}(n)}
$$

where $n=1, \ldots, N_{\text {ana }}$ is the rank of the ordered RMSEs (the potential analogue $a_{p}(n)$ with the smallest RMSE had rank $n=1$ ). The weighted mean forecast anomalies, $a_{f}(m)$, for each month $m=1, \ldots, D_{f}$ in the forecast duration, $D_{f}$, formed the last part of the constructed analogue, $a_{c}$, and were calculated as:

$$
a_{f}(m)=a_{c}\left(D_{\text {ana }}+m\right)=\sum_{b-1}^{N_{\text {ana }}} w(b) a_{p, b}\left(D_{\text {ana }}+m\right),
$$


where $a_{p, n}$ is the vector of inflow anomalies for the potential analogue with rank $n$. The $D_{\text {ana }}, N_{\text {ana }}$, and $D_{f}$ were set to 5,5 , and 1 , respectively.

\subsection{Variation Analogue Method}

The VAM was developed and used to forecast the reservoir inflow in this study. The idea behind this method emerged from the concept of a force system. Consider a force system in which two objects are located at different locations and subjected to different forces. If we observe both objects through a small window and notice that they move to the same location at the same time, we cannot assume that the next location of these objects after some time interval will be the same. This is because they are subjected to different forces and start moving from different initial locations. This is similar to most forecasting methods in hydrology and meteorology that try to compare historical amounts of rainfall, discharge, runoff, or inflow to forecast future values of the data of interest. If similarities in the values of the data of interest are the result of different forcing factors and different initial conditions, the forecasting result may be worse than expected. Compare this to another force system in which two objects are located at different locations but are subjected to the same force. In this system, at the same time interval, the objects will again move to different locations. However, although the new locations of the two objects are different, their displacement will be equal. If we compare the displacements of the objects instead of their locations, we can predict that in the next time interval of interest the two objects will have the same displacement. Consequently, the locations of the two objects can be calculated from their predicted displacement. Based on this concept, the forecasting method known as VAM was developed in this study. This method compares the variation (displacement) in standardized inflows instead of comparing standardized inflows as in the WMAM. It replaces data points by their successive differences so that the model target is shifted towards prediction based on differences rather than absolute positioning. By this method, a measure of chronological stability around a suitably chosen statistical quantity is established based on long-term data calculation. Considering the standardized monthly anomalies $\left(a_{t}\right)$ as calculated in Equation (1), the variation $\left(v_{t}\right)$ in $a_{t}$ can be calculated as:

$$
v_{t}=a_{t}-a_{t-1}
$$

Once the observed data for the latest month have been received and the variation $\left(v_{t}\right)$ has been calculated, this variation is compared to all possible historical sequences of variations covering the same months of the year. From this annual series of potential variation analogues $\left(v_{\text {ana }}\right)$, the $N_{\text {ana }}$ historical variation analogues most similar to the recent variation are selected. The variation for the next month can then be forecast as:

$$
v_{t+1}=\frac{1}{N_{a n a}} / \sum_{n=1}^{N_{\text {ana }}}\left[v_{t}+v_{\text {ana }(t+1)}-v_{\text {ana }(t)}\right]
$$

Then, the forecast standardized monthly anomaly for the next month can be calculated as:

$$
a_{t+1}=v_{t+1}+a_{t}
$$

Comparison of the variation in standardized inflows is similar to comparison of the displacement of objects subjected to a force-if the objects have the same properties and are subjected to the same force, their displacement will be the same, regardless of their initial locations. Building on this concept, if the displacement of one of these objects is known, it is possible to predict the displacement of the other objects. Applying this to inflow forecasting, if the variation in inflow in the current month of the current year is similar to the variation in inflow in the same month of a historical year, the inflows of the two years are inferred to occur due to similar forcing factors. If it is assumed that these forcing factors persist, the variation in inflow in the next month of the current year can be forecast from the variation in inflow of the historical year. Using this method, reservoir inflows are standardized as 
in the WMAM forecasts. Then, the variation in standardized inflows between successive months is calculated and used in forecasting as described above.

\section{Results}

The forecasting using the WANN model in this study was begun by finding the input parameters of the ANN model that produced the best forecast. After several trials, the best forecasting results were obtained from a model with 22 input parameters, as shown in Table 2. The activation function of this model in both the hidden and output layers was a hyperbolic function. The number of hidden neurons, learning rate, and momentum that provided the best results were $10,0.0001$, and -0.5 , respectively. After obtaining the best forecast from the ANN model, all input parameters were decomposed into their detailed (high frequency) and approximated (low frequency) components. Then, all decomposed components were fed into the neural network model. The performance indicators of the WANN model in each model period are shown in Table 3.

Table 2. Input parameters of the artificial neural network (ANN) model that produced the best forecast. SOI: Southern Oscillation Index; DMI: Dipole Mode Index.

\begin{tabular}{ccc}
\hline Input Parameter & SST Region/Ocean Index Name & Lag Used (Month) \\
\hline & Niño 1+2 & $5,17,18$ \\
Sea-surface temperature & Niño 3 & $4,16,17$ \\
& Niño 3.4 & $5,15,16$ \\
& Pacific Ocean & $6,7,18$ \\
& South China Sea & $6,18,19$ \\
& Andaman Sea & $7,18,19$ \\
\hline \multirow{2}{*}{ Ocean index } & SOI & 5 \\
Reservoir inflow & DMI & 16 \\
\hline
\end{tabular}

Table 3. Performance indicators of the wavelet artificial neural network (WANN) model. CD: coefficient of determination; EI: efficiency index; RMSE: root mean square error; R: correlation.

\begin{tabular}{ccccc}
\hline \multirow{2}{*}{ Model Period } & \multicolumn{4}{c}{ Model Performance Indicators } \\
\cline { 2 - 5 } & RMSE & R & EI & CD \\
\hline Training & 179.85 & 0.95 & 0.90 & 0.89 \\
Validation & 248.68 & 0.90 & 0.81 & 0.85 \\
Testing & 210.80 & 0.95 & 0.89 & 0.77 \\
\hline
\end{tabular}

For the forecasting using the WMAM and VAM methods, reservoir inflow data from 1974 to 2004 were used to forecast the inflow of the years 2005 to 2014. Therefore, there were at least 31 years of monthly records for use as historical analogues. For the WMAM method, the selection of potential historical analogues was based on calculation of the RMSE as described in the Methodology section. Figure 3 shows an example of reservoir inflow forecasting for March 2013. Five historical analogues gave the minimum root mean square values selected for the forecast. After selection, the weights for each analogue were calculated, and these weights were then used to calculate the forecast standardized value and converted to obtain the forecast inflow for March 2013. The yellow broken line and the yellow solid line are the forecast and observed standardized inflows in March 2013, respectively. The forecast standardized inflows were converted to inflows in a normal form and used to calculate the performance indicators.

Figure 4 shows an example of the variation values plotted against standardized inflow values from February to January of the following year. Assuming that the most current month is December 2005, we can forecast the inflow in January 2006. The variation from March to January of previous years is plotted alongside the variation from March to December of 2005. Then, the most similar 
variation analogue is selected by comparing the variation vectors from November to December. In this example, the most similar analogue is the plot for 1993-1994, as shown in Figure 4. Thus, the variation in January 2006 is calculated from the variation in December 1993 and January 1994. Then, the forecast standardized value for January 2006 is calculated from this forecast variation value, as shown in Figure 4. The plot of standardized inflows from October 2005 to January 2006 is very similar to the plot from October 1993 to January 1994. It is evident from the plot that VAM forecasting has the advantage that it allows determination of similar patterns among inflow events even if they occurred in different zones. This is different from the WMAM, in which selection of potential historical dialogues depends on the RMSE between inflows of previous years and the current year. The selection will include all nearby inflow patterns even if they are not similar to the inflow pattern of the current year, while similar patterns in different zones, as in this example, will not be selected.

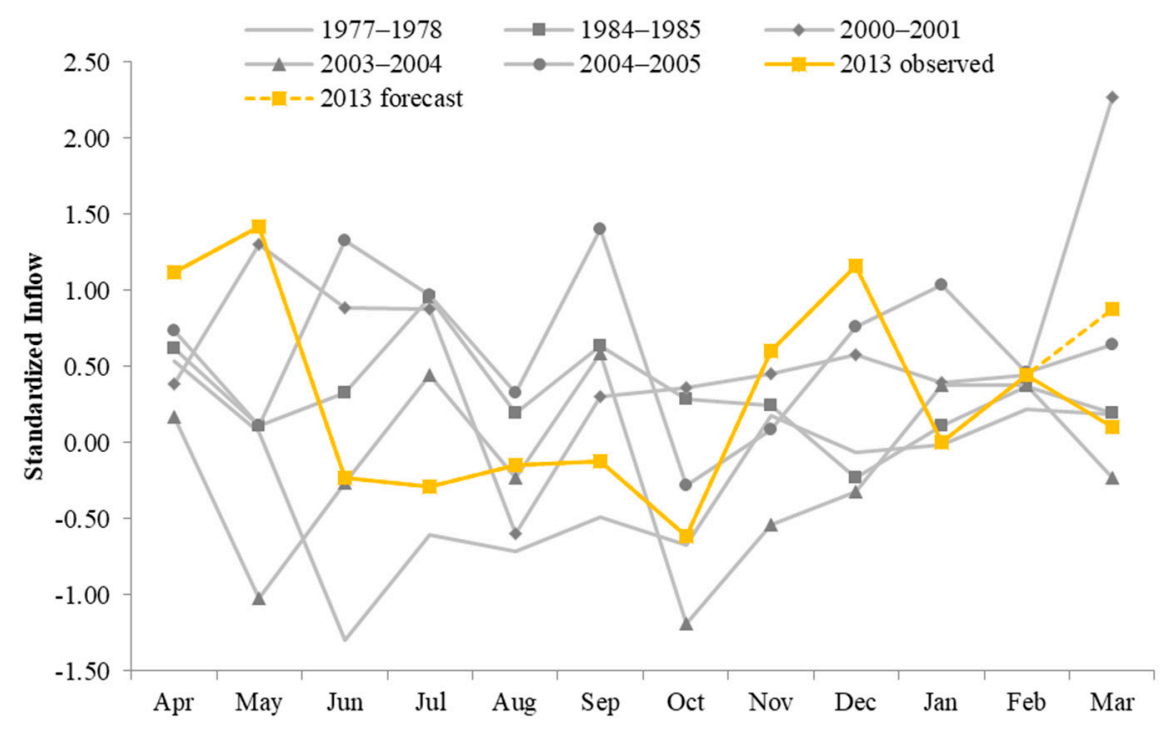

Figure 3. Forecasting of the reservoir inflow in March 2013 using the weighted mean analogue method.

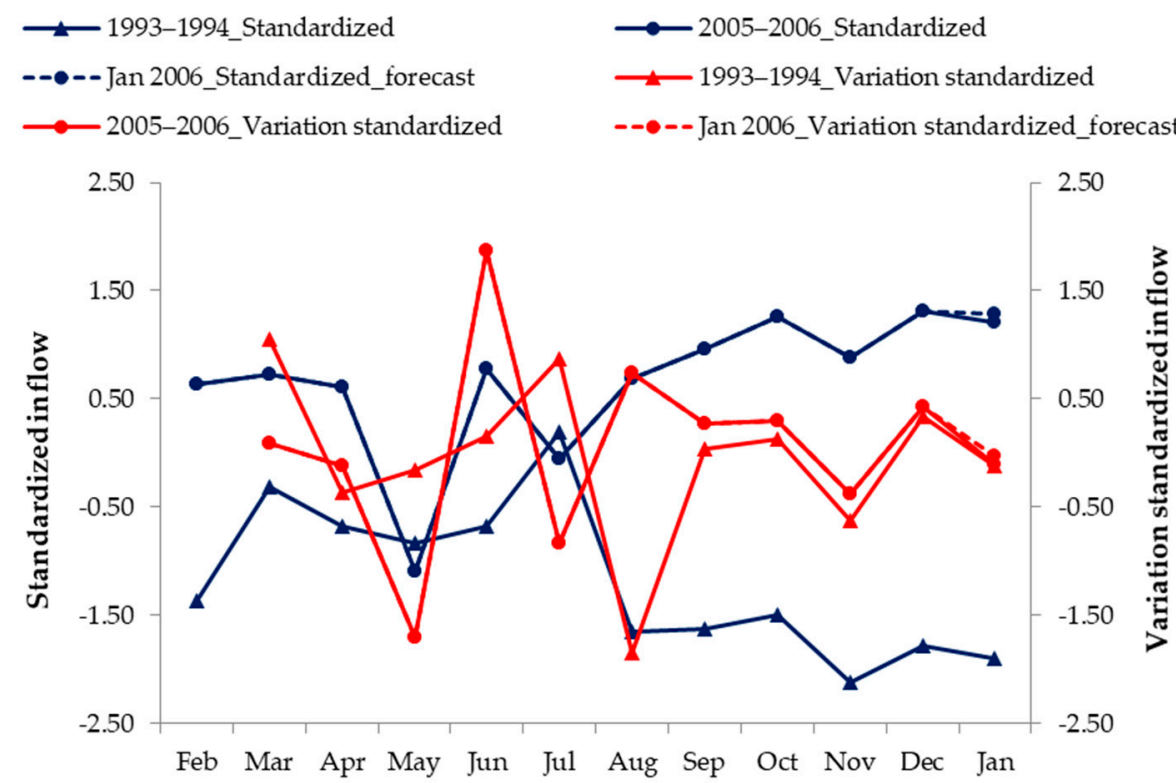

Figure 4. Variation and standardized values of inflows used for forecasting inflow in January 2006. 
To improve forecasting results of the VAM, additional processes to assist selection of the most similar analogue were investigated. Consider the predicted inflow of the Sirikit Dam in August 1995, which was the most extreme Sirikit Dam inflow on record, shown in Figure 5. The plot of the variation in standardized inflow for June-July 1995 is very similar to the plot for the same period in 1992. The forecast variation in standardized inflow in August 1995 should follow the red dotted line. Nevertheless, the actual variation followed the dark red line, which is very far from the forecast result. These observations indicate that the VAM still has some weaknesses and requires further improvement.

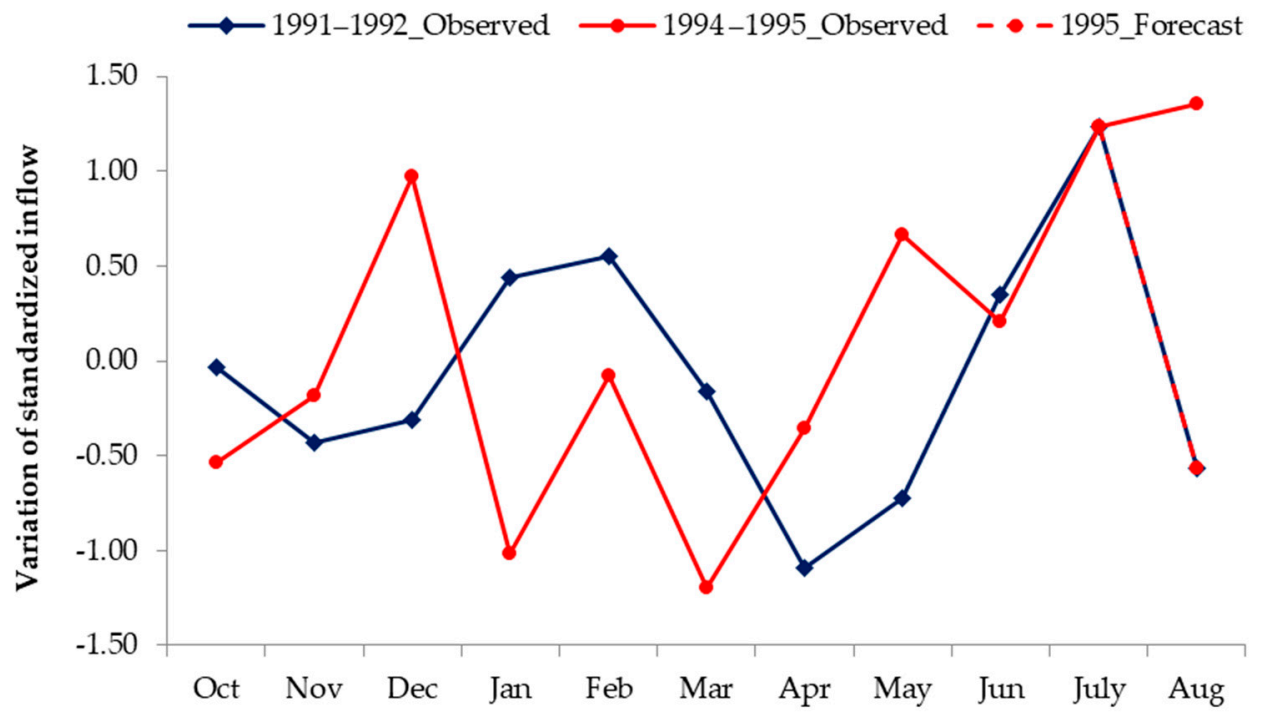

Figure 5. Plot of variation in standardized inflow forecasts for August 1995.

Several previous studies have indicated that SSTs and climatic indices are associated with climate and rainfall in Thailand. Moreover, several previous studies have reported that incorporating SSTs and climatic indices into river-flow forecasts can improve results. The incorporation of SSTs and climatic indices as inputs to the WANN in this study confirmed that these data can improve reservoir inflow forecasts, implying that SST and climatic indices are also associated with reservoir inflow. Based on this assumption, years with similar patterns of standardized inflow variation should have similar SST and climatic-index patterns. These similar SST and climatic-index patterns can then act as guidelines in the selection of the most potentially useful historical analogues. Therefore, cross-correlation analysis between SSTs and the climatic indices used as the inputs of the WANN model and standardized inflow was performed. The correlation values between SSTs, climatic indices, and standardized inflow were calculated for each month. The SSTs and climatic indices with correlation values exceeding the threshold for significance (0.304 for 41-year inflow data in this study) [44] were considered significant SSTs and indices in the selection of historical analogues of the corresponding month. As examples, Appendix A lists the significant SSTs and climatic indices for the Sirikit Dam inflows in January and August; the number -1 behind a month indicates the month in the previous year compared to the year of inflow. For example, Niño 3 (Jan-1) refers to the Niño 3 index in January of the previous year compared to the year of the inflow to be forecast. These significant SSTs and climatic indices will be used to decide the most useful potential historical analogue for forecasting the inflow of the current year.

An example of forecasting the inflow of the Sirikit Dam in January 2008 is presented. In this case, the most current month is December 2007, and the inflow to forecast is that of January 2008. The steps of forecasting the inflow are as follows.

1. The variations in standardized inflows for March to December 2007 are plotted along with the variations in standardized inflows for March to January of the available analogues. Potential 
analogues with variation patterns similar to that of December 2007 are selected. In this case, there are three historical analogue candidates: December 1976, December 1988, and December 1989 (Figure 6).

2. To forecast the inflow for January 2008, the significant SSTs and climatic indices for inflows in January 2008, January 1977, January 1989, and January 1990 are plotted to assist in selection of the best potential analogue (see Appendix B). In this case, most of the significant climatic indices and SSTs for January 2008 are very similar to those for January 1989, and therefore January 1989 is selected as the best potential analogue.

3. The forecast variation for January 2008 is calculated from the variation in January 1989 using Equation (6) and plotted as the red-dotted line in Figure 6.

4. After obtaining the variation for January 2008, the standardized inflow is calculated using Equation (7) and converted to the normal form of inflow. The forecast inflow values calculated from this method and the observed inflow in January 2008 are 138.29 and 136.84 million cubic meters, respectively.

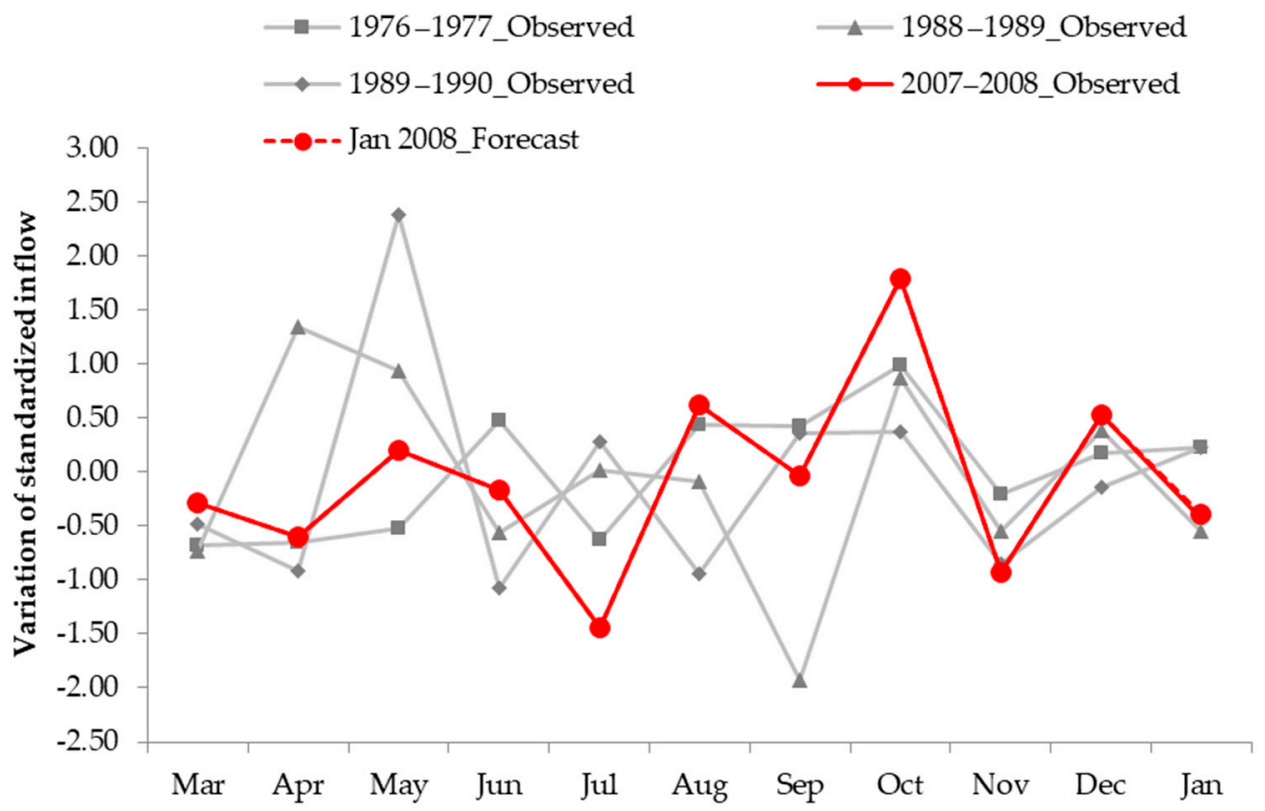

Figure 6. Plot of variation in forecasts of the Sirikit Dam inflow in January 2008.

For a greater understanding of forecasting using the VAM with the consideration of SSTs and climatic indices (the VAM-improved), the readers can read the examples of forecasting for the inflow in August 1995 and August 2011, which were the most extreme inflows on record (Appendices C and D, respectively).

Based on the results described above, the improved VAM that considers climatic indices was used to forecast July, August, and September, which are high-flow periods in Sirikit Dam inflow. The forecasting performance of all methods for the whole-year and high-flow periods was evaluated and compared. To compare the performance of the WANN with other methods, the forecasting results of the WANN in the validation and testing periods were combined and the performance indicators were recalculated to match the forecasting period of the WANN with that of the WMAM and VAM. The performance indicators of all methods in predicting the reservoir inflow of the Sirikit Dam from January 2005 to December 2014 are shown in Table 4. Plots of forecast and observed inflows for the whole-year and high-flow periods are shown for comparison in Figures 7 and 8, respectively. 
Table 4. Performance indicators of all forecasting methods for forecasting the Sirikit Dam inflow in 2005-2014. VAM: variation analogue method; WANN: wavelet artificial neural network; WMAM: weighted mean analogue method.

\begin{tabular}{cccccc}
\hline \multirow{2}{*}{ Forecasting Period } & \multirow{2}{*}{ Method } & \multicolumn{4}{c}{ Model Performance Indicator } \\
\cline { 3 - 6 } & & RMSE & R & EI & CD \\
\hline \multirow{3}{*}{ Whole year } & WANN & 234.20 & 0.92 & 0.85 & 0.81 \\
(January-December) & WMAM & 335.45 & 0.84 & 0.69 & 0.62 \\
& VAM & 186.33 & 0.95 & 0.90 & 1.01 \\
& VAM-improved & 115.55 & 0.98 & 0.96 & 0.92 \\
\hline \multirow{2}{*}{ High flow } & WANN & 366.78 & 0.83 & 0.67 & 0.60 \\
(July-September) & WMAM & 627.42 & 0.37 & 0.04 & 0.37 \\
& VAM & 305.59 & 0.84 & 0.84 & 0.87 \\
& VAM-improved & 215.55 & 0.95 & 0.92 & 0.86 \\
\hline
\end{tabular}

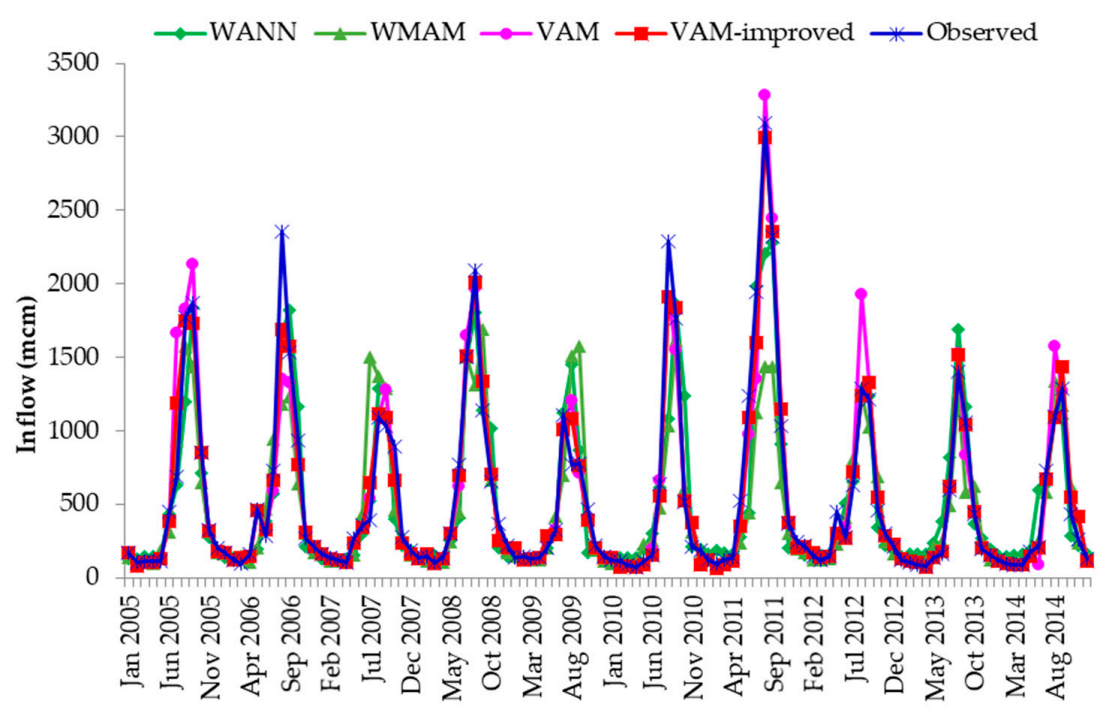

Figure 7. Comparison of plots of forecast and observed inflows for whole-year periods from 2005 to 2014.

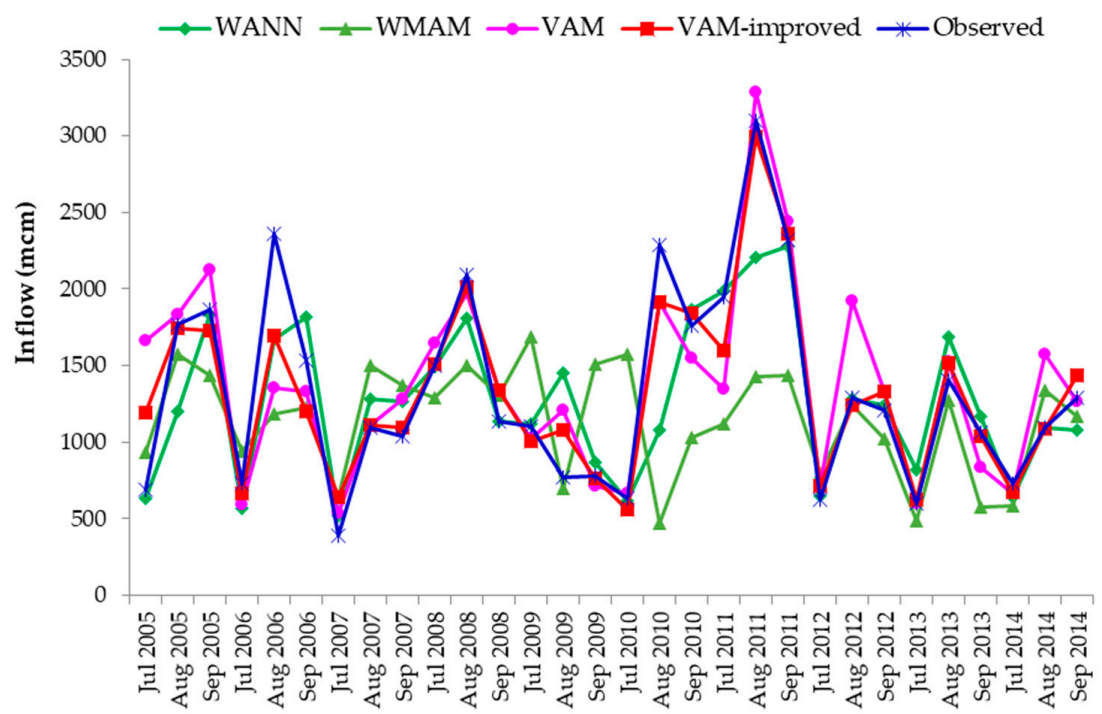

Figure 8. Comparison of plots of forecast and observed inflows in high-flow periods from 2005 to 2014. 
For the whole-year forecasting period, which included both low-flow and high-flow patterns, the WANN model provided good forecasting results as all performance indicators were above 0.80 . The WMAM provided only satisfactory forecasting results, as the EI and CD values were $<0.70$ and the RMSE was higher than for the other methods. The forecasting performance of the VAM was superior to that of other methods as all performance indicators were $>0.9$ and the RMSE had the lowest value. It can also be seen from the comparison plot in Figure 8 that the VAM forecast captured the extreme inflow of the Sirikit Dam reservoir.

For the high-flow period, the forecasting performance of all methods significantly worsened. The WANN method, which produced good results for the overall period, provided only satisfactory results for this period. This was not unexpected; poor performance in predicting peak flow is a common weakness of ANN methods, as noted in several previous reports (e.g., Sudheer [34]; Yang et al. [35]). The forecasting performance of the WMAM was markedly lower in the high-flow period compared to the whole year, indicating that this method is not suitable for prediction of inflow in a high-response watershed, especially for the high-flow season, as in this case. This weakness of the WMAM was also noted by Svensson [31], who reported a high degree of uncertainty in the historical analogue approach, particularly in catchments with a rapid response. The VAM captured flow best in this period comparing to the WANN and the WMAM, especially peak flow. Taking SSTs and climatic indices into consideration significantly improves forecasting results of the VAM. The VAM-improved performance indicators were the best in both the whole-year and high-flow forecasting periods; this model provided very good performance indicators even in high-flow periods, with all indicators having values above 0.85. The improvement can be seen in Figure 8, where most of the VAM-improved forecast values are closer to the observed values than those of the standard VAM (i.e., the VAM without consideration of SSTs and climatic indices).

Based on the very high reliability and low uncertainty of the improved VAM indicated by the results, this method can be used for management of the Sirikit Dam, especially in high-flow periods. It provides very good forecasting results, with all performance indicators above 0.85 , and its uncertainty as defined by RMSE values is less than the reservoir surcharge storage $\left(998,000,000 \mathrm{~m}^{3}\right)$. Moreover, in testing, it predicted extreme flow such as occurred in August 2011, whereas other methods did not. However, in forecasting based on historical analogues, there may be high-return-period events for which no suitable analogues are available. Therefore, scenarios based on forecasts with various uncertainty values should be modeled. The most suitable scenario for the current month can then be selected for dam operation. For example, if the water level in the dam is very low in August, well below the upper curve of the reservoir operation rule, and low inflow is forecast in September, then a scenario with less inflow than that forecast is selected to retain the water for the coming dry season. On the other hand, if the water level in the dam is very high in August, close to the upper curve of the reservoir operation rule, and high inflow is forecast in September, then a scenario with more inflow than that forecast is selected. The dam operator can then decide to release water gradually to make space for the expected inflow. For the low-flow season, the forecasting results of all of the methods examined in this study were acceptable for dam operation, as their uncertainties were close enough to observed values. Moreover, most of the inflow in the low-flow period is kept for water supply, so uncertainty is less important.

\section{Discussion and Conclusions}

This study compared three forecasting methods-the WANN method, the WMAM, and the VAM-for use in forecasting the monthly reservoir inflow of the Sirikit Dam in Thailand. The results indicate that for whole-year forecasting, which includes both low- and high-flow seasons, the WANN method provided good results, while those obtained using the WMAM were only satisfactory. The performance of the VAM was superior to that of the other methods and accurately predicted extreme inflow. For the high-flow period (July-September), the VAM predicted flow best, especially in the case of peak flow. However, the performance of all of the methods was significantly lower for 
the high-flow period. The WANN method, which produced good results for whole-year forecasts, provided only satisfactory results for the high-flow period. The performance of the WMAM method was markedly worse in the high-flow period compared to the whole-year period. Based on the results of this study, the following conclusions were reached with regard to the methodologies and application to Sirikit Dam in Thailand.

1. The WANN model, a hybrid of ANN and wavelet analysis, produced good results in forecasting the monthly reservoir inflow of Sirikit Dam. However, for the high-flow period it provided only satisfactory results. This indicated that the WANN model is weak in forecasting peak flows because such flows are rare compared to low- and moderate-flow events. As ANN-based models rely on learning from past events, the number of peak flow events is insufficient for ANN models to learn and produce good forecasting results. This characteristic of ANN-based models is a common issue that has been reported in the literature (e.g., Sudheer [34]; Yang et al. [35]). Wavelet analysis, a data pre-processing technique, generally improved the forecasting results, but the improvement was not enough to predict peak flow. In conclusion, the WANN method has a poor ability to forecast peak flows.

2. The WMAM provided only reasonably satisfactory predictions for the whole-year period and its performance was markedly worse in the high-flow period. This may have been because the forecasting is dependent on the RMSE between historical and current inflows. The selection of historical analogues based on RMSE may result in the inclusion of all recent inflow patterns, even if they are not similar to the pattern of the current year. This leads to incorrect selection of analogues, especially for a high-response catchment such as the Sirikit Dam. This characteristic of analogue-based methods such as the WMAM was reported previously by Svensson [31], who concluded that the uncertainty of the historical analogue approach can be large, especially in catchments with a fast response.

3. The developed VAM provided excellent predictions of the monthly reservoir inflow of the Sirikit Dam. Its ability to forecast extreme peak flow represented an advantage over the other methods. However, it has the drawback that it relies on past observation data. Therefore, in the absence of a similar historical analogue it may not provide good results. This is especially important in the case of events with return periods that may be longer than the record length, making rare situations that have not been observed in the past very difficult to forecast. The example of this situation is the case of forecasting the inflow in August 1995 described earlier. In addition, changes in land use, urbanization processes, or changes in the morphology of the rivers may affect the discharge arriving to the reservoirs. The study of the effect of those changes should be further conducted to clarify this issue.

4. The incorporation of SSTs and climatic indices in the WANN model and the VAM significantly improved forecasts. In the WANN model, SSTs and climatic indices were used as an input to the model. In the VAM, significant SSTs and climatic indices for the inflow each month were plotted and compared to aid in selecting appropriate historical analogues. The idea behind investigating use of SSTs and climatic indices as guidelines for selection of the most suitable historical analogues was derived from the results of several previous studies that indicated that SSTs and climatic indices were associated with the Thai climate and rainfall (e.g., Singharattna et al. [36]; Bejranonda and Koch [37]; Chansaengkrachang [38]; Bridhikitti [39]; and Manusthiparom [40]). The improvement in forecasts in this study after incorporation of SSTs and climatic indices supports these previous reports. However, future studies should clarify the individual contributions of SSTs and the climate indexes.

5. Although the VAM could provide excellent predictions of the reservoir inflow of the Sirikit Dam, the leading time of prediction in this study is only one month, which may not be enough for the open large reservoir where prediction times of longer than one month are often needed. The further study of longer lead-time prediction using the VAM is hence needed for better reservoir operation. 
Author Contributions: Conceptualization, S.A. and S.K.; Methodology, S.A.; Validation, S.A., S.Y. and S.K.; Formal analysis, S.A.; Data curation, S.A.; Writing—original draft preparation, S.A.; Writing—review and editing, S.A., S.Y., and S.K.; Supervision, S.K.; Project administration, S.K.; Funding acquisition, S.K.

Funding: The first author was provided a research grant by the Agricultural Research Development Agency (ARDA) of Thailand. This research was tremendously supported by Advancing Co-design of Integrated Strategies with Adaptation to Climate Change (ADAP-T) Project through the Science and Technology Research Partnership for Sustainable Development (SATREPS) by the Japan Science and Technology Agency and the Japan International Cooperation Agency (JST-JICA). It was also supported by the Japan Society for the Promotion of Science (JSPS) KAKENHI Grant Number JP16H06291.

Conflicts of Interest: The authors declare no conflict of interest.

\section{Appendix A}

Table A1. Significant SSTs and climatic indices for Sirikit Dam Inflow in January and August. SCS: South China Sea; AO: Arctic Oscillation.

\begin{tabular}{|c|c|c|c|}
\hline \multicolumn{2}{|c|}{ January } & \multicolumn{2}{|l|}{ August } \\
\hline $\begin{array}{c}\text { Significant } \\
\text { SSTs/Indices }\end{array}$ & Correlation & Significant SSTs/Indices & Correlation \\
\hline Andaman (MAR-1) & -0.404 & Andaman (AUG) & -0.321 \\
\hline Andaman (APR-1) & -0.366 & Andaman (MAY-1) & -0.372 \\
\hline Andaman (MAY-1) & -0.400 & Andaman (JUN-1) & -0.336 \\
\hline Andaman (JUN-1) & -0.320 & $\mathrm{AO}(\mathrm{FEB}-1)$ & -0.345 \\
\hline Andaman (JUL-1) & -0.342 & $\mathrm{AO}(\mathrm{DEC}-1)$ & -0.308 \\
\hline Andaman (AUG-1) & -0.556 & $\mathrm{AO}(\mathrm{MAY})$ & -0.356 \\
\hline Andaman (SEP-1) & -0.499 & DMI (APR) & 0.312 \\
\hline Andaman (OCT-1) & -0.303 & DMI (MAR-1) & 0.325 \\
\hline Andaman (NOV-1) & -0.371 & DMI (APR-1) & 0.421 \\
\hline Andaman (DEC-1) & -0.325 & DMI (MAY-1) & 0.324 \\
\hline Niño 3 (JAN-1) & -0.375 & SOI (MAR) & 0.448 \\
\hline Niño 3 (FEB-1) & -0.422 & Niño 1 + 2 (MAR) & -0.316 \\
\hline Niño 3 (MAR-1) & -0.391 & Niño 1 + 2 (APR) & -0.440 \\
\hline Niño 3 (APR-1) & -0.388 & Niño $1+2$ (MAY) & -0.404 \\
\hline Niño 3.4 (Jan-1) & -0.398 & Niño 1 + 2 (JUN) & -0.342 \\
\hline Niño 3.4 (FEB-1) & -0.403 & Niño 1 + 2 (JUL) & -0.307 \\
\hline Niño 3.4 (MAR-1)) & -0.422 & Niño $1+2$ (AUG) & -0.334 \\
\hline Niño 3.4 (APR-1) & -0.459 & Niño 3 (MAR) & -0.330 \\
\hline Niño 3.4 (MAY-1) & -0.327 & Niño 3 (APR) & -0.421 \\
\hline Niño 4 (JAN-1) & -0.327 & Niño 3 (MAY) & -0.439 \\
\hline Niño 4 (FEB-1) & -0.321 & Niño 3 (JUN) & -0.357 \\
\hline Niño 4 (MAR-1) & -0.322 & Niño 3 (JUL) & -0.310 \\
\hline Pacific (FEB-1) & -0.339 & Niño 3 (AUG) & -0.329 \\
\hline Pacific (MAR-1) & -0.327 & Niño 3.4 (APR) & -0.318 \\
\hline Pacific (APR-1) & -0.325 & Niño 3.4 (MAY) & -0.353 \\
\hline Pacific (MAY-1) & -0.394 & Pacific (JUL) & -0.409 \\
\hline Pacific (JUN-1) & -0.487 & Pacific (AUG) & -0.355 \\
\hline Pacific (JUL-1) & -0.591 & & \\
\hline Pacific (AUG-1) & -0.544 & & \\
\hline Pacific (SEP-1) & -0.354 & & \\
\hline SCS (APR-1) & -0.334 & & \\
\hline SCS (MAY-1) & -0.320 & & \\
\hline SCS (JUN-1) & -0.346 & & \\
\hline SCS (JUL-1) & -0.361 & & \\
\hline SCS (AUG-1) & -0.340 & & \\
\hline SOI (JAN-1) & 0.362 & & \\
\hline SOI (FEB-1) & 0.412 & & \\
\hline SOI (MAR-1) & 0.531 & & \\
\hline SOI (APR-1) & 0.398 & & \\
\hline
\end{tabular}




\section{Appendix B}

(a)

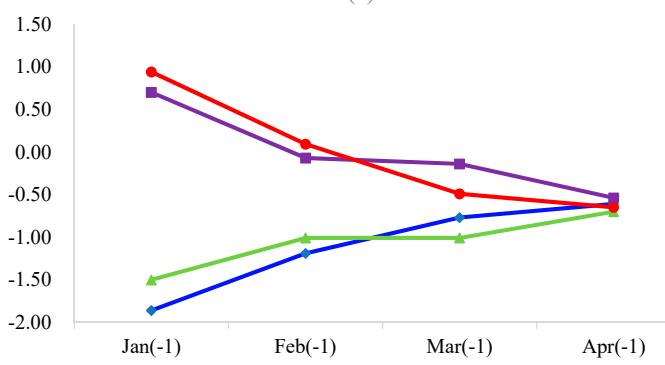

(c)

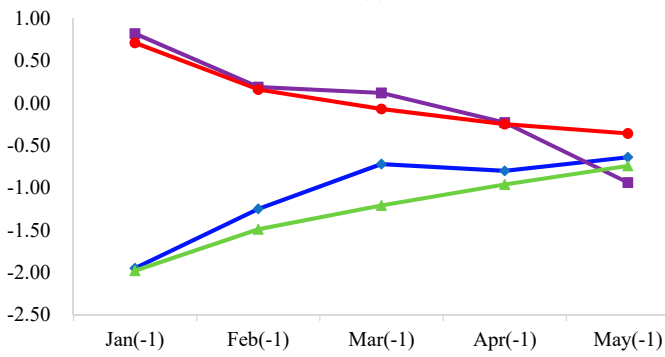

(e)

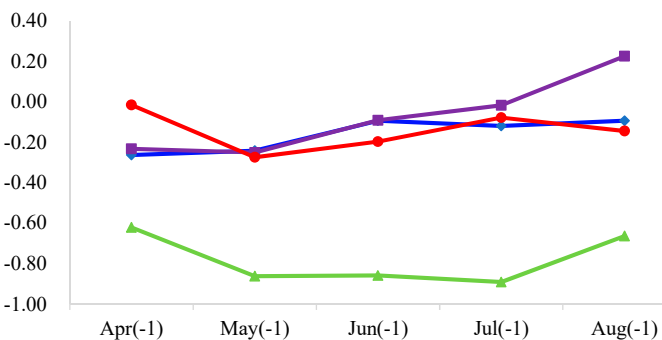

$(\mathrm{g})$

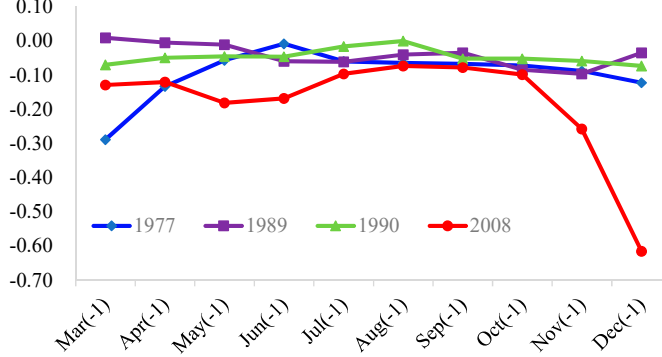

(b)

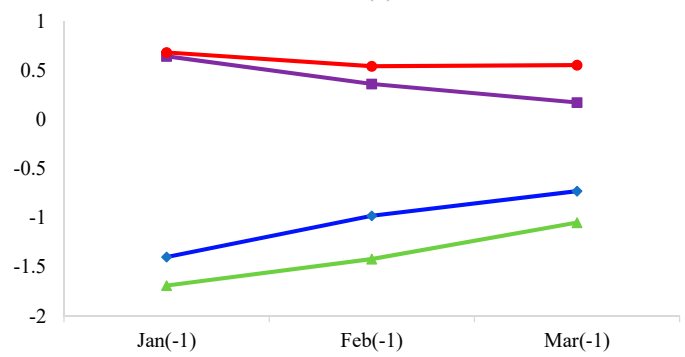

(d)

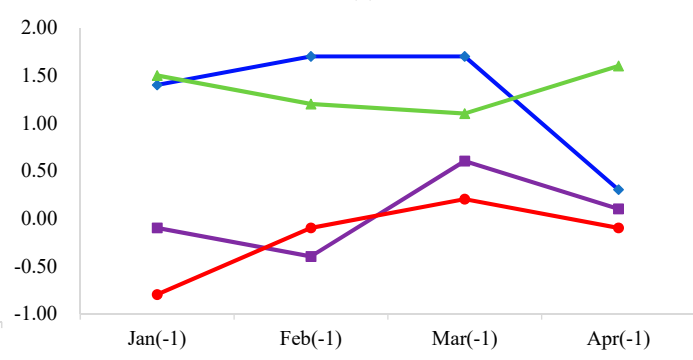

(f)

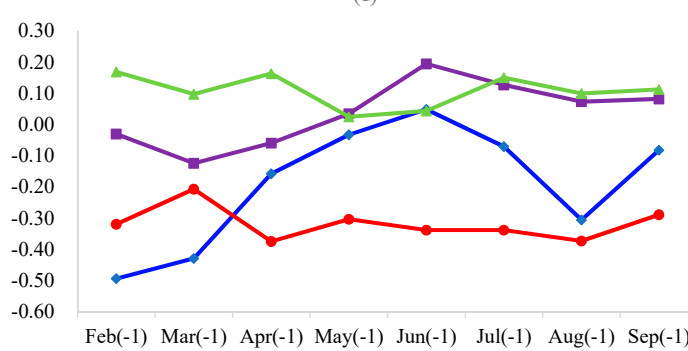

$\multimap 1977 \rightarrow-1989 \rightarrow 1990 \multimap 2008$

Figure A1. Plots of significant SSTs and climatic indices for forecasting Sirikit Dam inflow in January 2008 (a) Niño 3; (b) Niño 4; (c) Niño 3.4; (d) SOI; (e) Standardized SST in the South China Sea; (f) Standardized SST in the Pacific Ocean (g) Standardized SST in the Andaman sea.

\section{Appendix C}

The inflow forecasts for August 1995 using the VAM.

In the inflow forecasts for August 1995 described in the Results section, if we assume that all inflow data from 1974 to 2014 were available for prediction of inflow in August 1995 (which is impossible because 1996-2014 was in the future in August 1995), the potential variation analogues would be as plotted as in Figure A2. When considering the plots of significant SSTs and climatic indices for the inflow in August 1995 and all candidate analogues (see Figure A3), it is evident from the plots that most 
of the significant SSTs and climatic indices for August 1995 are similar to those for August 2001 and August 2013. It is also evident that the most significant SSTs and climatic indices for August 1992 differ from those for August 1995. Therefore, the variation in standardized inflow in August 1995 does not align with the variation in August 1992, even though it is the most visually similar among the available candidates. In this case, the variation in standardized inflow in August 1995 could be calculated from the variation in August 2001 and August 2013 using Equation (6). The forecast variation in August 1995 is shown by the red dotted line in Figure A2, which is closer to the observed value than before. This is the strength of the improved VAM that considers significant SSTs and climatic indices to predict extreme peak flow accurately.

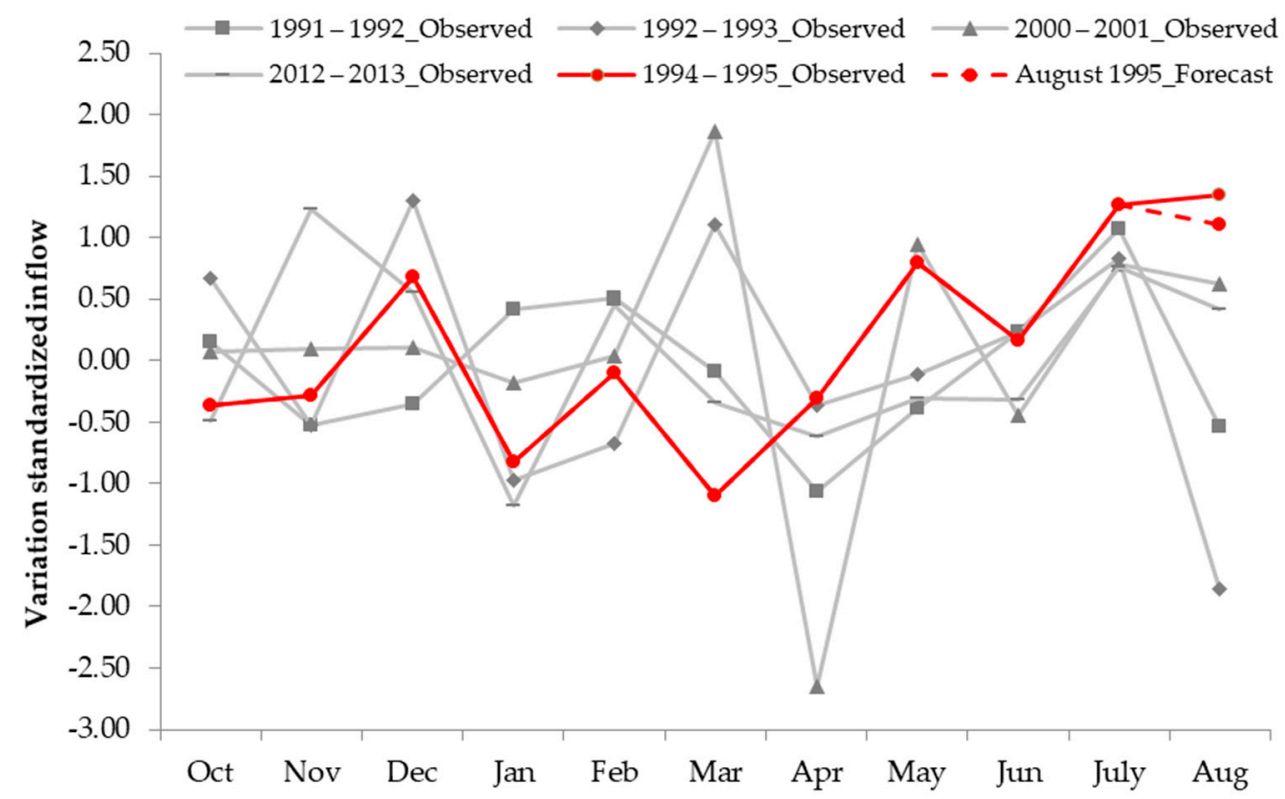

Figure A2. Plot of variation in forecasts of Sirikit Dam inflow in August 1995. 
(a)

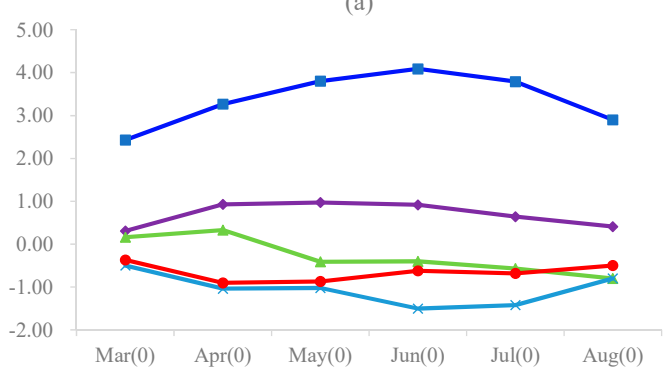

(c)

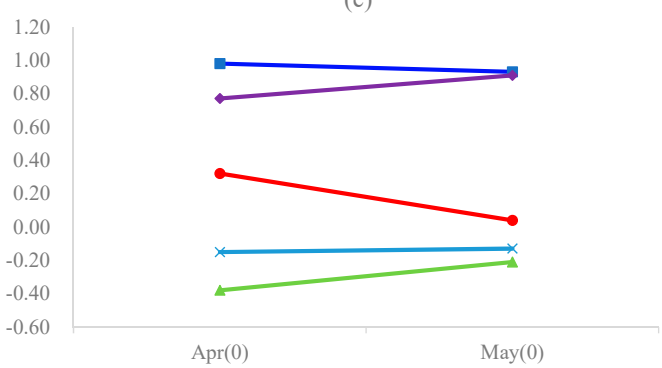

(e)

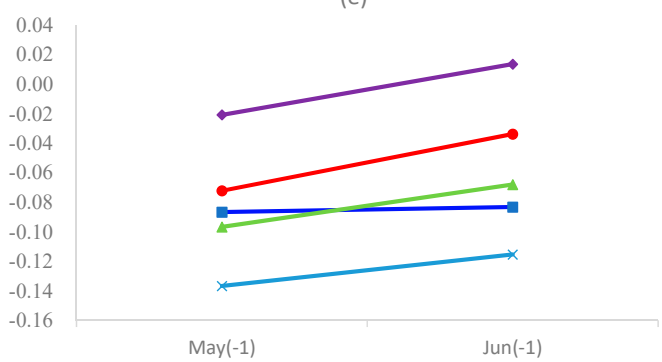

(g)

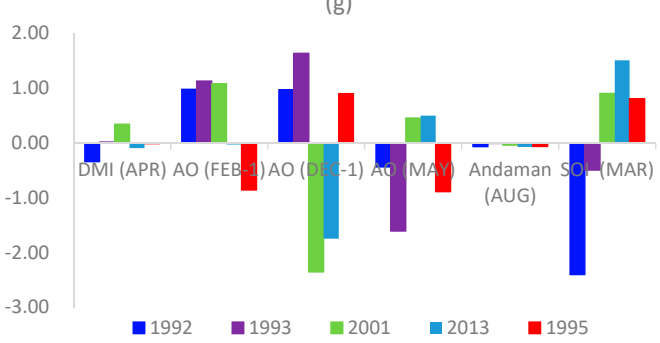

(b)

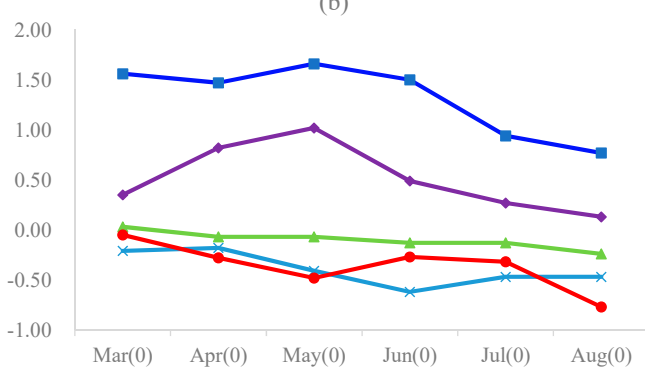

(d)

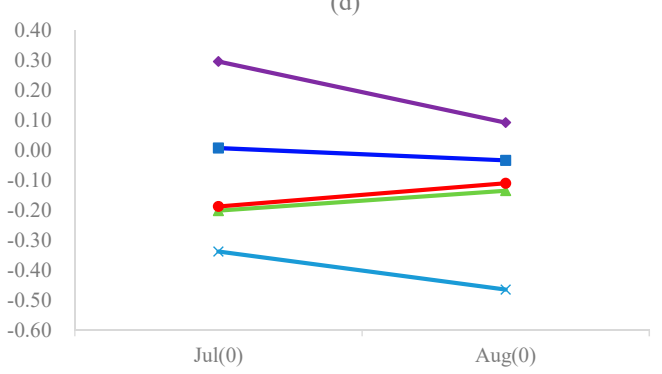

(f)
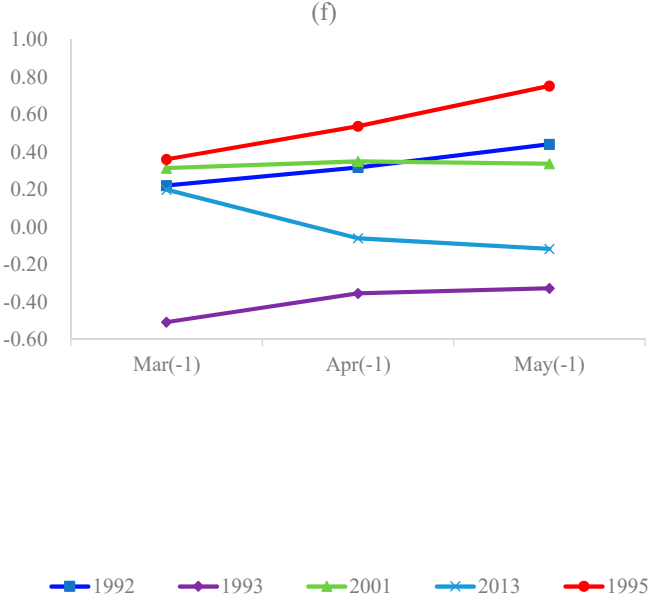

Figure A3. Plots of Significant SSTs and climatic indices for forecasting Sirikit Dam inflow in August 1995 (a) Niño 1 + 2; (b) Niño 3; (c) Niño 3.4; (d) Standardized SST in the Pacific Ocean; (e) Standardized SST in the Andaman Sea; (f) DMI; (g) Other SSTs and indices as stated in Appendix A.

\section{Appendix D}

The inflow forecasts for August 2011 using the VAM.

The inflow in August 2011 is another extreme event in the record. To confirm the ability of the VAM to predict extreme inflow, the forecast procedure for this extreme event is discussed. The prediction follows the steps described for the January 2008 inflow. Here, the most current month is July 2011, so we require a similar pattern of variation in July in the optimal analogue. Visual examination of the variation plots produces six potential analogues with patterns similar to that of July 2011 (see Figure A5). The significant SSTs and climatic indices for inflow in August 2011 and all candidate analogues are plotted to determine which analogue is the best potential candidate for forecasting (see Figure A6). The August 2011 patterns of SSTs and significant indices are not very similar to any one or two historical analogues, unlike the previous cases in the Results section. Therefore, the climate-forcing 
factors affecting the rainfall and inflow of the Sirikit Dam Basin in August 2011 are a mix of the forcing factors in the candidate analogue years. Based on this assumption, the variation in standardized inflow in August 2011 is the average of the variation in August of all candidate analogues and can be calculated using Equation (6). The results are shown by the red dashed line, which is very close to the observed value depicted by the dark red line (see Figure A5). This result confirms the strength of the improved VAM in forecasting extreme peak flows. In other methods that attempt to compare or search for historical inflow information, finding candidate analogues is very difficult, especially in the case of extreme events such as in August 2011, because the events occur in a very high-flow zone and similar events are very rare (see Figure A4).

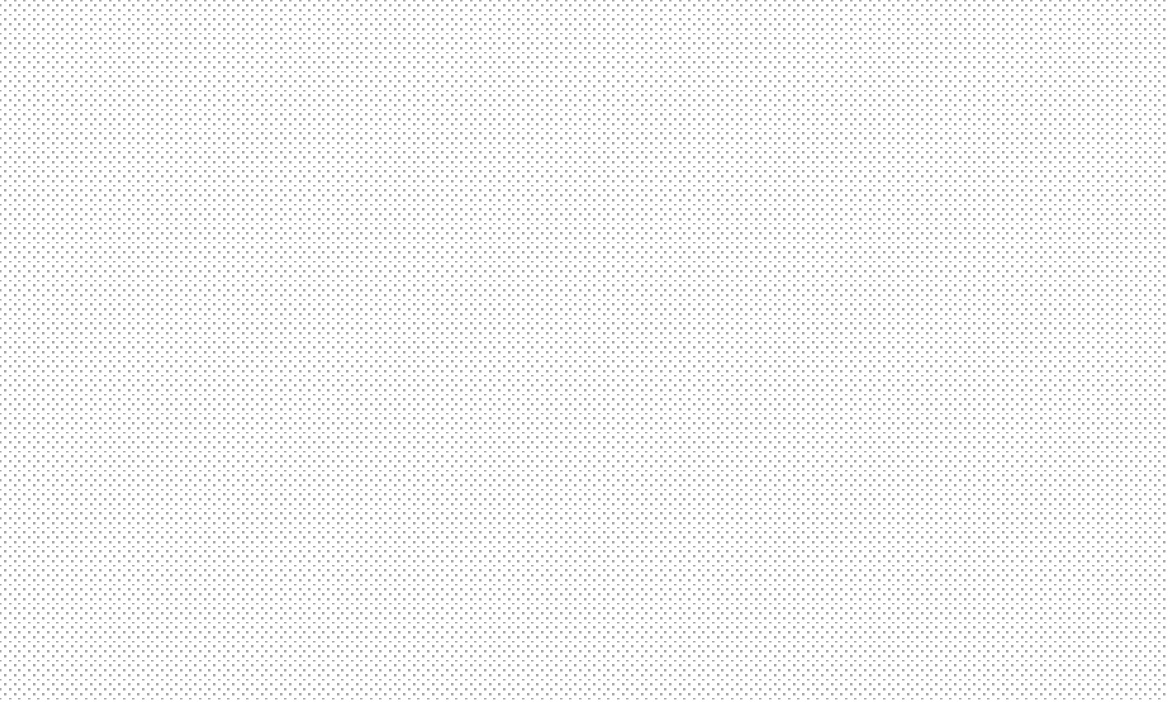

Figure A4. Plots of standardized inflow for forecasting Sirikit Dam inflow in August 2011.

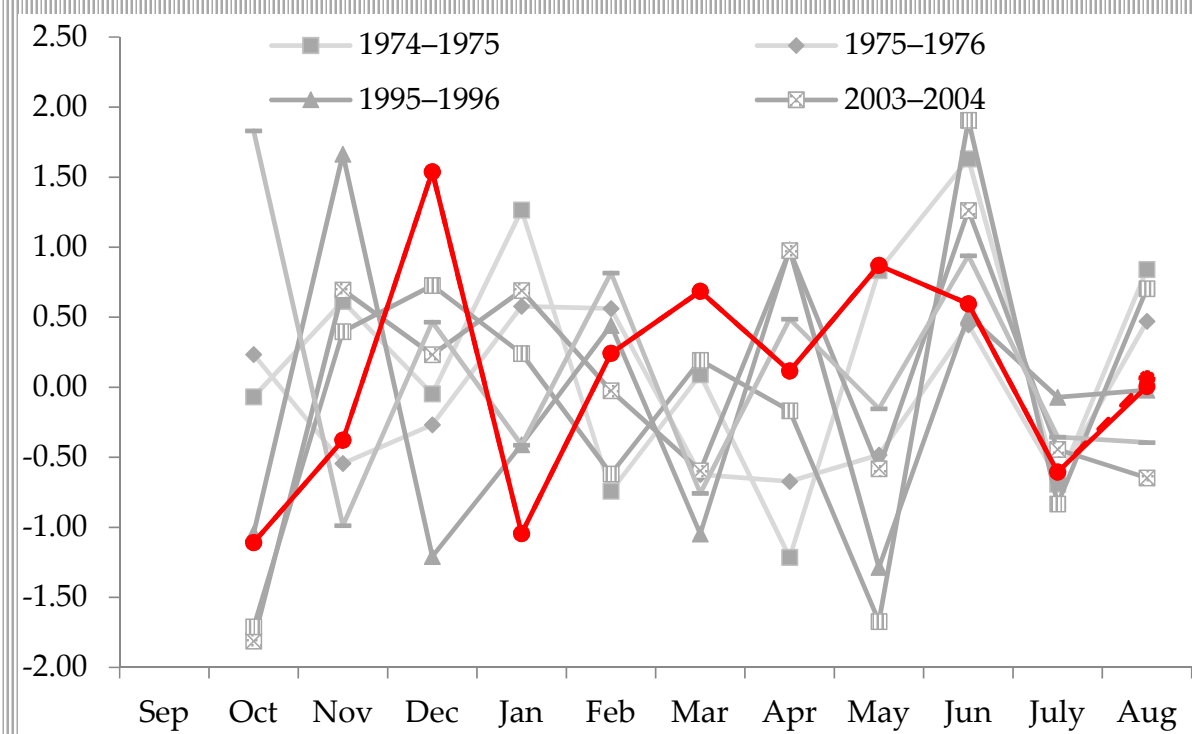

Figure A5. Plots of variation-standardized inflow for forecasting Sirikit Dam inflow in August 2011. 


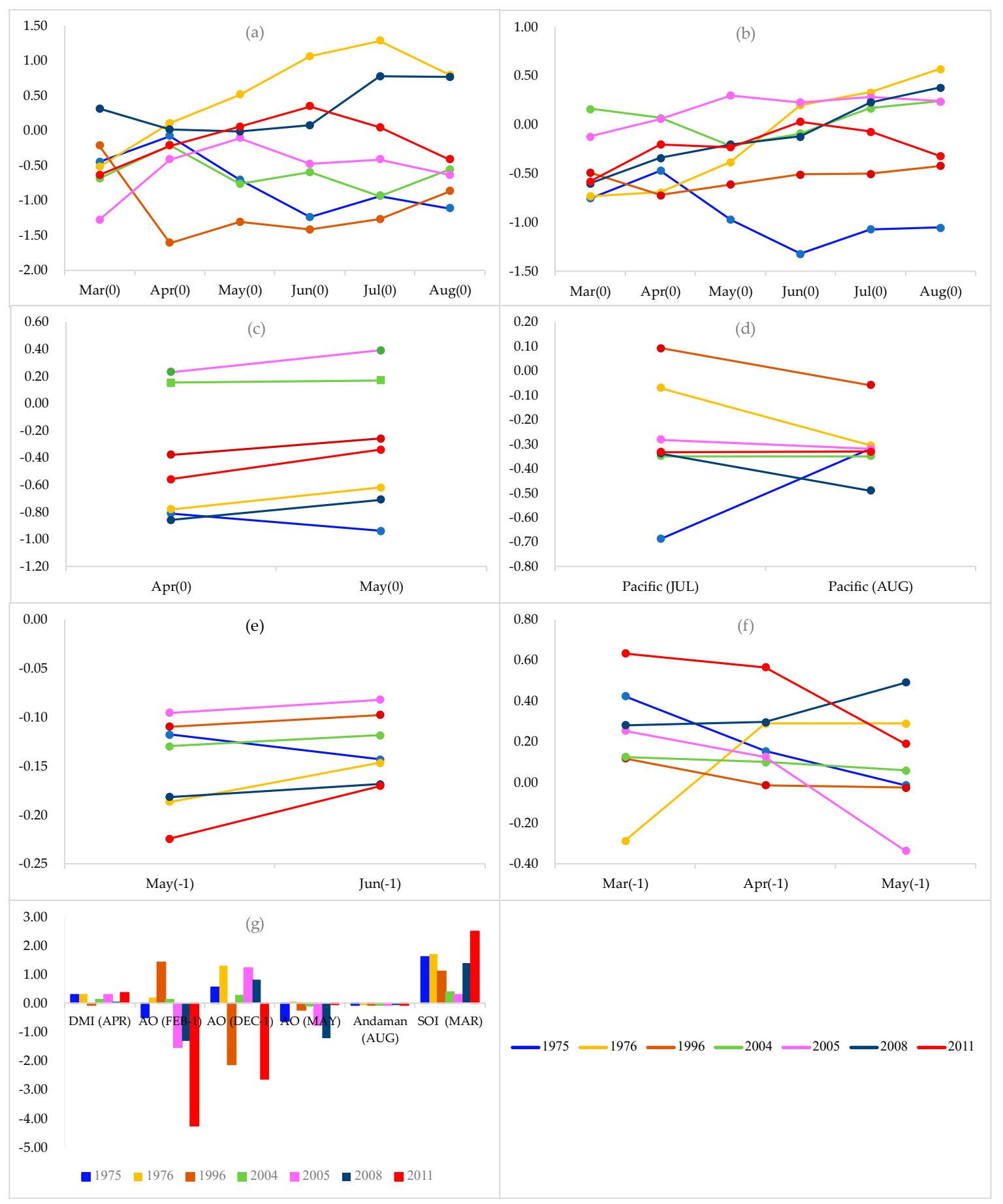

Figure A6. Plots of significant SSTs and climatic indices for forecasting Sirikit Dam inflow in August 2011 (a) Niño 1 + 2; (b) Niño 3; (c) Niño 3.4; (d) Standardized SST in the Pacific Ocean; (e) Standardized SST in the Andaman Sea; (f) DMI; (g) Other SSTs and indices as stated in Appendix A.

\section{References}

1. Anand, J.; Gosain, A.K.; Khosa, R. Optimisation of multipurpose reservoir operation by coupling SWAT and genetic algorithm for optimal operating policy (case study: Ganga River basin). Preprints 2018. [CrossRef]

2. Schleiss, A.J.; Franca, M.J.; Juez, C.; De Cesare, G. Reservoir sedimentation vision paper. J. Hydraul. Res. 2016. [CrossRef]

3. US Army Corps of Engineers. Forecast-Based Advance Release at Folsom Dam: Effectiveness and Risk-Phase 1; PR-48; Hydrologic Engineering Center: Davis, CA, USA, 2002; pp. 1-111. 
4. Kumar, T. Operations Research in Water Quality Management; Harvard Water Resources Group: Cambridge, UK, 2013.

5. Lin, S.-C.; Wu, R.-S.; Chen, S.-W. Study on optimal operating rule curves including hydropower purpose in parallel multireservoir systems. WIT Trans. Ecol. Environ. 2005, 83, 151-160.

6. Mateo, C.M.R.; Hanasaki, N.; Komori, D.; Yoshimura, K.; Kiguchi, M.; Champathong, A.; Yamazaki, D.; Sukhapunnaphan, T.; Oki, T. A simulation study on modifying reservoir operation rules: Tradeoffs between flood mitigation and water supply. IAHS Publ. 2013, 362, 33-40.

7. Mythili, B.; Devi, U.G.; Raviteja, A.; Kumar, P.S. Study of optimizing techniques of reservoir operation. Int. J. Eng. Res. Gen. Sci. 2013, 1, 2091-2730.

8. Heydari, M.; Othman, F.; Taghieh, M. Optimization of multipurpose reservoir system operations by using matrix structure (case study: Karun and Dez Reservoir Dams). PLoS ONE 2016, 10, e0156276. [CrossRef] [PubMed]

9. Mohammed, J.M. Recalibration of Kainji Reservoir operating rules for optimal operation. Ann. Rev. Res. 2018, 1, 1-7.

10. Sivapragasam, C.; Vasudevan, G.; Vincent, P. Effect of inflow forecast accuracy and operating time horizon in optimizing irrigation releases. Water Resour. Manag. 2007, 21, 933-945. [CrossRef]

11. Dong, X.; Dohmen-Janssen, C.M.; Booij, M.; Hulscher, S. Effect of flow forecasting quality on benefits of reservoir operation. A case study for the Geheyan reservoir (China). Hydrol. Earth Syst. Sci. Discuss. 2006, 3, 3771-3814. [CrossRef]

12. Wang, Y.; Guo, S.; Chen, H.; Zhou, Y. Comparative study of monthly inflow prediction methods for the Three Gorges Reservoir. Stoch. Environ. Res. Risk Assess. 2013, 28, 555-570. [CrossRef]

13. Mohammadi, K.; Eslami, H.R.; Dardashti, S.D. Comparison of regression, ARIMA and ANN models for reservoir inflow forecasting using snowmelt equivalent (a case study of Karaj). J. Agric. Sci. Technol. 2005, 7, 17-30.

14. ASCE Task Committee on Application of Artificial Neural Networks in Hydrology. Artificial neural networks in hydrology. I: Preliminary concepts. J. Hydrol. Eng. 2000, 5, 115-123. [CrossRef]

15. ASCE Task Committee on Application of Artificial Neural Networks in Hydrology. Artificial neural networks in hydrology. II: Hydrologic applications. J. Hydrol. Eng. 2000, 5, 124-137. [CrossRef]

16. Kim, T.; Choi, G.; Heo, J.-H. Inflow Forecasting for real-time reservoir operation using artificial neural network. In Proceedings of the World Environmental and Water Resources Congress, Kansas City, MO, USA, 17-21 May 2009; pp. 4947-4955.

17. Zhang, J.; Cheng, C.-T.; Liao, S.-L.; Wu, X.-Y.; Shen, J.-J. Daily reservoir inflow forecasting combining QPF into ANNs model. Hydrol. Earth Syst. Sci. Discuss. 2009, 6, 121-150. [CrossRef]

18. Othman, F.; Naseri, M. Reservoir inflow forecasting using artificial neural network. Int. J. Phys. Sci. 2011, 6, 434-440. [CrossRef]

19. Valipour, M.; Banihabib, M.E.; Behbahani, S.M.R. Monthly inflow forecasting using autoregressive artificial neural network. J. Appl. Sci. 2012, 12, 2139-2147. [CrossRef]

20. Vijayakumar, N.; Vennila, S. Reservoir inflow forecasting at Krishnagiri Reservoir Project using artificial neural network. In Proceedings of the National Conference on Contemporary Advancements in Civil Engineering Practices-CACEP, P.S.G College of Technology, Coimbatore, India, 23 May 2016.

21. Muluye, G.Y.; Coulibaly, P. Seasonal reservoir inflow forecasting with low-frequency climatic indices: A comparison of data-driven methods. Hydrol. Sci. J. 2007, 52, 508-522. [CrossRef]

22. Kim, T.-W.; Valdés, J.B. A nonlinear model for drought forecasting based on conjunction of wavelet transforms and neural networks. J. Hydrol. Eng. 2003, 8, 319-328. [CrossRef]

23. Amnatsan, S.; Kuribayashi, D.; Jayawadena, A.W. Application of artificial neural networks and wavelet analysis in prediction of water level in Nan River of Thailand. In Proceedings of the Annual Conference 23rd Annual Conference, Hosei University, Tokyo, Japan, 7 September 2010.

24. Zhao, Z.; Giannakis, D. Analog forecasting with Dynamics-Adapted Kernels. Nonlinearity 2016, 29, 2888-2939. [CrossRef]

25. Zhao, B.; Zhai, P. A new forecast model based on the analog method for persistent extreme precipitation. Weather Forecast. 2016, 31, 1325-1341. [CrossRef]

26. Horton, P.; Obled, C.; Jaboyedoff, M. The analogue method for precipitation prediction: Finding better analogue situations at a sub-daily time step. Hydrol. Earth Syst. Sci. 2017, 21, 3307-3323. [CrossRef] 
27. Matulla, C.; Zhang, X.; Wang, X.L.; Wang, J.; Zorita, E.; Wagner, S.; Storch, H.V. Influence of similarity measures on the performance of the analog method for downscaling daily precipitation. Clim. Dyn. 2008, 30, 133-144. [CrossRef]

28. Obled, C.; Bontron, G.; Garçon, R. Quantitative precipitation forecasts: A statistical adaptation of model outputs through an analogue sorting approach. Atmos. Res. 2002, 63, 303-324. [CrossRef]

29. Diomede, T.; Nerozzi, F.; Paccagnella, T.; Todini, E. The use of meteorological analogues to account for LAM QPF uncertainty. Hydrol. Earth Syst. Sci. 2008, 12, 141-157. [CrossRef]

30. Bellier, J.; Zin, I.; Siblot, S.; Bontron, G. Probabilistic flood forecasting on the Rhone River: Evaluation with ensemble- and analogue-based precipitation forecasts. E3S Web Conf. 2016, 7, 1-11. [CrossRef]

31. Svensson, C. Seasonal river flow forecasts for the United Kingdom using persistence and historical analogues. Hydrol. Sci. J. 2016, 61, 19-35. [CrossRef]

32. Panagoulia, D. Artificial neural networks and high and low flows in various climate regimes. Hydrol. Sci. J. 2006, 51, 563-587. [CrossRef]

33. Komori, D.; Nakamura, S.; Kiguchi, M.; Nishijima, A.; Yamazaki, D.; Suzuki, S.; Kawasaki, A.; Oki, K.; Oki, T. Characteristics of the 2011 Chao Phraya River flood in Central Thailand. HRL 2012, 6, 41-46. [CrossRef]

34. Sudheer, K.P.; Nayak, P.C.; Ramasastri, K.S. Improving peak flow estimates in artificial neural network river flow models. Hydrol. Process. 2003, 17, 677-686. [CrossRef]

35. Yang, T.; Asanjan, A.A.; Welles, E.; Gao, X.; Sorooshian, S.; Liu, X. Developing reservoir monthly inflow forecasts using artificial intelligence and climate phenomenon information. Water Resour. Res. 2017, 53, 2786-2812. [CrossRef]

36. Singhrattna, N.; Babel, M.S.; Perret, S.R. Hydroclimate variability and its statistical links to the large-scale climate indices for the Upper Chao Phraya River Basin, Thailand. Hydrol. Earth Syst. Sci. Disscuss. 2009, 6, 6659-6690. [CrossRef]

37. Bejranonda, W.; Koch, M. The role of ocean state indices in seasonal and inter-annual climate variability of Thailand. In Proceedings of the 1st Symposium on Sustainable Water Management and Climate Change, Nakhon Pathom, Thailand, 16-17 June 2010.

38. Chansaengkrachang, K. Empirical orthogonal function analysis of rainfall over Thailand and its relationship with the Indian Ocean Dipole. Chiangmai Univ. Int. Conf. 2011, 1, 47-54.

39. Bridhikitti, A. Connections of ENSO/IOD and aerosols with Thai rainfall anomalies and associated implications for local rainfall forecasts. Int. J. Climatol. 2013, 33, 2836-2845. [CrossRef]

40. Manusthiparom, C. Hydroclimatic Prediction for Integrated Water Resources Management in the Chao Phraya River Basin in Thailand. Ph.D. Thesis, University of Tokyo, Tokyo, Japan, September 2003.

41. Panagoulia, D.; Tsekouras, G.J.; Kousiouris, G. A multi-stage methodology for selecting input variables in ANN forecasting of river flows. Glob. Nest J. 2017, 19, 49-57.

42. Wang, G.; Guo, L.; Duan, H. Wavelet Neural Network Using Multiple Wavelet Functions in Target Threat Assessment. Sci. World J. 2013, 2013. [CrossRef] [PubMed]

43. Vidakovic, B.; Mueller, P. Wavelets for Kids: A Tutorial Introduction; Duke University: Durham, NC, USA, 1991; pp. 1-28.

44. Boslaugh, S. Statistics in a Nutshell, 2nd ed.; O'Reilly Media, Inc.: Sebastopol, CA, USA, 2013; pp. $173-192$. ISBN 978-1-449-31682-2.

(C) 2018 by the authors. Licensee MDPI, Basel, Switzerland. This article is an open access article distributed under the terms and conditions of the Creative Commons Attribution (CC BY) license (http:/ / creativecommons.org/licenses/by/4.0/). 